\title{
FEMININO, MISTICISMO E LITURGIA NA POÉTICA DE CRUZ E SOUSA
}

Osmar Pereira Oliva Universidade Estadual de Montes Claros

\begin{abstract}
Resumo: A produção poética de Cruz e Sousa apresenta, com frequência, elementos litúrgicos, ritualísticos, por meio de metáforas sinestésicas e de vocabulário "celestial", o que amplia e intensifica a atmosfera simbolista dos seus textos. Em muitos de seus poemas, a mulher é descrita associada a esses elementos religiosos e místicos; no entanto, essas construçôes não devem ser entendidas essencialmente como manifestaçôes da religião católica. Este trabalho pretende discutir as representaçôes do feminino e a simbologia ritualistica e litúrgica a partir da dimensão mistica e naturalista em poemas de Cruz e Sousa, a fim de comprovar que a presença de imagens e simbolos religiosos reflete a busca do transcendental e não se vincula a uma religiāo, especificamente.

Palavras-chave: Representaçôes do feminino, Misticismo, Liturgia.
\end{abstract}

João da Cruz e Sousa nasceu no dia 24 de novembro de 1862, na antiga cidade de Desterro, atual Florianópolis, capital de Santa Catarina. Foi mesmo um assinalado, desde o seu nascimento: filho de dois negros escravos alforriados, sua vida foi marcada pelos signos da tragédia. O poeta sofreu a 
hostilidade de uma sociedade preconceituosa, que não o reconheceu como o grande artista que foi, ensombrado pela cor da pele que ele soube estilizar em sua poesia. Sentiu a dor de ver a esposa Gavita enlouquecer e, por último, foi vitimado pela tuberculose, morrendo aos 36 anos, na localidade de Sítio, atual município de Antônio Carlos - MG.

Em 1893, publicou os livros Missal (prosa) e Broquéis (poesia). Depois de sua morte, por empenho de seus amigos, entre os quais se destaca Nestor Vítor, foram publicados Evocações (prosa, 1898), Faróis (poemas, 1900) e Últimos sonetos (1905). É necessário dizer que poucos críticos deram a devida atenção à prosa de Cruz e Sousa. Ainda assim, quando os estudiosos de literatura se voltaram para esse poeta, dedicaram-se quase exclusivamente aos poemas de Faróis e Broquéis, sem muita preocupação com a sua prosa, fato que ainda hoje se comprova. Além desses silêncios por parte da crítica, não raras vezes notam-se equívocos, como o que se refere à presença da cor branca, de estrelas e demais astros celestes em sua poesia, que sinalizaria um desejo de sublimação, de superação de sua cor negra e da sua condição de homem humilde e pobre. ${ }^{1}$

Outros equívocos são percebidos nos críticos do século XIX, que apontavam um fechamento da poética de Cruz e Sousa, também comum nos demais simbolistas, o que redundou nas desgastadas expressões "torre de marfim" e "nefelibatas". Não se trata aqui de fazer uma reabilitação do poeta em estudo, mas de trazer à luz alguns pontos contraditórios nas análises de sua obra. Cruz e Sousa não foi um alienado em seu tempo; ao contrário, além dessa poesia de cunho espiritual, metafísico, como pretendo discutir um pouco mais adiante, podemos afirmar que o poeta escreveu em favor da causa republicana e abolicionista, como se comprova no seguinte trecho de um artigo seu, publicado no jornal $O$ Moleque, em 12 de outubro de 1885 : $^{2}$

A abolição, a grande obra do progresso é uma torrente que se despenca: não há mais pôr-lhe embaraços à sua carreira vertiginosa.

As consciências compenetram-se dos seus altos deveres e caminham pela vereda da luz, pela vereda da Liberdade, igualdade e fraternidade, essa trilogia enorme, pregada pelo filósofo do Cristianismo e ampliada pelo

1. A esse respeito, cf. BASTIDE. A poesia afro-brasileira e NUNES. Cruz e Sousa e o mito do poeta como herói moral.

2. SOUSA. Ô Catarina!, p. 15. 
autor dos Châtiments - o velho Hugo. (...)

É aí que desaparece nas noites da história os Carlos I e Luiz XVI, as Maria Antonieta e Rainha Isabel, é aí que desaparece o cetro, para dar lugar à república, a única forma de governo compatível com a dignidade humana...

Como se vê, há um tom político e engajado em Cruz e Sousa que pouco foi discutido até hoje. Por fim, na esteira desses equívocos, chego ao motivo da escrita deste ensaio. A poética de Cruz e Sousa apresenta elementos dos rituais litúrgicos que fazem parte dos rituais católicos, mas que não devem ser tidos como pertencimentos exclusivos dessa religião. A dimensão espiritualista presente em sua obra pode ser considerada metafísica, de caráter transcendental e, até mesmo, esotérica, mas não essencialmente católica. Segundo Affonso Romano de Sant'Anna, em O canibalismo amoroso (1993), podemos destacar em Broquéis visões místicas, como aparecem em "Cristo de Bronze", "Regina Coeli", "Noiva da Agonia", "Aparição". Mas essas representações não se vinculam ao universo católico e devem ser entendidas como alegorias da incessante busca de ascensão espiritual, mística. Notamos, nesses poemas, o tema da religiosidade de caráter universal. Trata-se, no caso de Cruz e Sousa, de uma poética voltada para os mistérios da alma, revelando um desejo de sublimação, através do culto das formas vagas, imprecisas.

Dessa forma, essas imagens não podem se restringir ao universo católico, pois elas remetem ao plano metafísico, destituído de divindades. A esse respeito, já comentou o crítico francês Roger Bastide que a poética de Cruz e Sousa filia-se à estética platônica, da contemplação e das correspondências, teorizadas na poética de um precursor do simbolismo, Baudelaire, que tanto influenciou nosso poeta catarinense:

A natureza é um templo onde vivos pilares

Podem deixar ouvir confusas vozes:

E estas fazem o homem passar através de florestas

De símbolos que o vêem com olhos familiares. ${ }^{3}$

Assim como Baudelaire, Cruz e Sousa almeja a transcendência, em sua ânsia de atingir o mundo espiritual, através da floresta de símbolos, espaço

3. BAUDELAIRE. As flores do mal, p. 94. 
dos paralelos e das correspondências. Lembremos o belo e exemplar poema "O Assinalado":

Tu és o Poeta, o grande Assinalado

Que povoas o mundo despovoado

De belezas eternas pouco a pouco

$\mathrm{Na}$ Natureza prodigiosa e rica

Toda a audácia dos nervos justifica

Os teus espasmos imortais de louco! ${ }^{4}$

Nesse poema, percebe-se com mais clareza essa visão do poeta como um ser especial, escolhido pelos deuses (no plural mesmo). Convém assinalar, no entanto, a interpretação de Affonso Romano de Sant'Anna sobre esse tema:

Para Cruz e Sousa, em "Visão da Morte", a mulher é expressamente a "Noiva do Sepulcro, solitária / branca e sinistra no clarão dos círios” (...) após notar que o corpo de argila da amada apodrece, ele aguarda que ela ressurja de outra forma, como a "Bela das Belas, na Beleza / do transcendentalismo da Pureza / nas brancas imortais ressurreições". E aí, ao renascer, limpa desse corpo pecaminoso, ela será a "Regina Coeli" mística que, aliás, seria tema na moderna poesia de Jorge de Lima, e que mereceria ser estudada comparativamente. Rainha dos céus imaginários, "Regina Coeli" é a "Virgem branca, Estrela dos Altares, rosa pulcra dos Rosais polares...

Retomando ainda os elementos religiosos na poética desse autor, o termo "Antífona", que intitula o poema considerado a profissão de fé da poesia simbolista, não é um elemento da religião católica, como pode supor algum leitor da obra poética de Cruz e Sousa. Segundo Aurélio Buarque de Holanda Ferreira, "Antífona. 1. Curto versículo recitado ou cantado pelo celebrante, antes e depois de um salmo, e ao qual respondem alternadamente duas metades do coro." Nessas incursões pelo Aurélio, chama-nos a atenção o termo "salmo", de

4. SOUSA. Poesias completas de Cruz e Sousa, p. 102.

5. SANT'ANNA. O canibalismo amoroso, p. 170-171 (grifos nossos).

6. FERREIRA. Dicionário da língua portuguesa, p. 151. 
origem hebraica, relativo a um conjunto de 150 poemas registrados no Antigo Testamento, cuja autoria é atribuída ao rei Davi, filho de Jessé. Como se sabe, a Igreja Católica tem sua sede em Roma e seus dogmas são bem mais recentes do que os ensinamentos e escritos hebraicos. Os salmos aparecem frequentemente em rituais de outras religiões. Portanto, não é um elemento religioso particular dos rituais católicos.

Por outro lado, o termo "incenso", que tanto aparece na poética de Cruz e Sousa, também não tem essa conotação particular de um ritual católico. Como bem sabemos, o incenso era utilizado nas civilizações antigas não apenas para perfumar ambientes e garantir um certo efeito de espiritualidade e mistério, mas também para embalsamar corpos de pessoas importantes como faraós, reis e governantes. Além disso, o incenso é largamente utilizado em cerimônias de origem orientais, que nada têm a ver com o catolicismo. Assim, seria ingênuo de nossa parte desconsiderar a origem, a legitimidade e a anterioridade dos costumes orientais por consequência de nossas parcas limitações religiosas ocidentais. Segundo Sérgio Alves Peixoto:

Antífona é um versículo que se entoa antes de um salmo ou de um cântico religioso, devendo ser repetido pelos fiéis, inteiramente em coro. Nele, portanto, já estão presentes elementos que irão caracterizar a poesia simbolista, isto é, o religioso e o musical. Nessa antífona de Cruz e Sousa, o clima de religiosidade não tem nada a ver propriamente com uma crença divina, tendo o poeta, como a grande maioria dos poetas simbolistas, se apropriado dos "símbolos externos do culto" para valorizar a idéia de uma poesia feita de mistério, como uma forma de manter, pelo verso, a noção de um mundo que deve ser experimentado somente pela intuição dos recursos simbólicos.

Ao referir-se a "Virgens e Santas Vaporosas", Cruz e Sousa não estaria pensando no imaginário em torno da Virgem, mãe de Cristo, construída pela Igreja Católica, cuja representação, para essa doutrina, é Maria, esposa de José da Galileia. O termo utilizado no plural evoca a imagem das muitas mulheres que não puderam ser tocadas pelo sujeito poético, corpos femininos

7. PEIXOTO. A consciência criadora na poesia brasileira - do Barroco ao Simbolismo, p. 266. 
que se esvaem em sombras, vapores e perfumes. Cabe ressaltar que essas configurações do feminino vão se contrapor às imagens satânicas, naturalistas, herdadas de Baudelaire.

O soneto "Cristo de Bronze" servirá de contracanto aos dogmas e mitos da religião católica. Nesse poema, o eu lírico desmitifica a fé cega em cristos esculpidos em madeira, ouro e barro - o que é comum em templos dessa religião -, denunciando as práticas religiosas atreladas ao comércio. Portanto, nesse soneto, Cruz e Sousa é muito mais cético e "ateu", se assim se pode entender, do que católico. Citemos alguns versos na perspectiva dessa desconstrução:

Cristos de pedra, de madeira e barro...

Ó Cristo humano, estético, bizarro,

Amortalhado nas fatais injúrias...

Na rija cruz aspérrima pregado

Canta o Cristo de bronze do Pecado,

Ri o Cristo de bronze das luxúrias!...

O poeta reelabora o mito do cristianismo do ponto de vista irônico, criticando a idolatria dos homens, os quais se desviam da prática religiosa e moral, restringindo-as a símbolos concretos, palpáveis, bem ao contrário da verdadeira adoração, de cunho espiritual. Como se vê, a substituição profana é clara: o que deveria ser da ordem do divino apresenta-se humano, bizarro; o que, tradicionalmente, fora tido como puro, casto e santo, é descrito maculado pelo pecado e pela luxúria. Segundo Ivone Daré Rabello:

Diante da falência de seus projetos e da desconfiança dos novos mitos do esclarecimento, chamem-se eles ciência positiva ou cristianismo, justificação da desigualdade ou promessa de um mundo fraterno, o poeta cria seus mitos particulares. Transgredindo dogmas arraigados na sociedade brasileira, afirma em símbolos um mundo à deriva, sem deuses; é sua aspiração a dissolver-se.

8. SOUSA. Poesias completas de Cruz e Sousa, p. 15-16.

9. RABELLO. Um canto à margem. Uma leitura da poética de Cruz e Sousa, p. 187. 
Acentua-se, portanto, a degradação do mito cristão como resultado da descrença do homem oitocentista, que já não espera mais a redenção pela ciência ou pelo cristianismo. Sob o signo do emparedamento, não resta outra saída ao poeta senão imergir no seu interior, buscando nessa viagem uma explicação para a sua permanência nesse tempo de conflito e de contradições. Em sua análise, tomando como símbolos Cristo e seu antípoda, a serpente, Ivone Daré Rabello assinala que a paródia da história sagrada revela ao homem que tudo é degradação e queda. Retomemos, então, a palavra do crítico Affonso Romano de Sant'Anna:

Estranhamente, embora a poesia simbolista tanto fale de monjas, freiras, santas e da vida conventual, praticamente é só Alphonsus de Guimaraens que desenvolve um pensamento sistemático próximo da mística católica. (...) É ele quem mais próximo se situa de uma linguagem onde a sublimação assume um espaço significativo. É evidente que no subsolo de seu texto está o desejo exposto; mas já nos títulos de seus livros se observa sua proposta, muito mais católica do que a da maioria de seus contemporâneos poetas.

Contrariando o sentimento religioso ocidental, Cruz e Sousa utiliza os signos cristãos e os transfigura em motivos estéticos que fomentarão a sua poética. O tom "insolente" com que lida com esses signos pode ser entendido como uma maneira de o poeta insinuar a sua revolta contra a elite burguesa, branca e católica que dominava a sociedade brasileira do século XIX. Marginalizado por essa elite, o poeta não aceita a religião e a cultura que ela impõe, pois que não vê nelas sua identificação: pobre e negro. Enquanto o Cristo de pedra, de madeira e de barro é visto amortalhado em injúrias, a voz poética clama sua não aceitação, seu inconformismo.

O que temos é a naturalização do Cristo, um rebaixamento desse deus que domina o Ocidente e parte do Oriente. É nessa descida que Cruz e Sousa representará o feminino. Afastando-se, pois, dessas imagens da sublimação, teremos várias representações naturalistas da mulher, como no poema "Lésbia":

Cróton selvagem, tinhorão lascivo

Planta mortal, carnívora, sangrenta,

Da tua carne báquica rebenta

A vermelha explosão de um sangue vivo. ${ }^{11}$

10. SANT'ANNA. O canibalismo amoroso, p. 180-181.

11. SOUSA. Poesias completas de Cruz e Sousa, p. 14 . 
Um movimento ambíguo se manifesta, pois, em sua poética: em alguns poemas, percebe-se o desejo de ascese, de sublimação, em direção ao mundo espiritual; em outros, o apego ao terreno - em poemas que expressam volúpia e desejos carnais. Em muitos dos poemas dessa segunda vertente, a mulher é descrita de forma naturalista, decadente, maldita e zoomorfizada:

As fascinantes, mórbidas dormências

Dos teus abraços de letais flexuras,

Produzem sensações de agres torturas,

Dos desejos as mornas florescências.

Braços nervosos, tentadoras serpes,

Que prendem, tetanizam como os herpes,

Dos delírios na trêmula coorte...

Essas imagens do feminino invertem o olhar do eu lírico, do sublime para o grotesco, e demonstram o conflito que ele vive, entre o espiritual e o carnal. Impossibilitado de atingir o plano metafísico, seu canto volta-se, raivosamente, para a mulher, símbolo material que o aprisiona ao plano terreno: "És a origem do Mal, és a nervosa / Serpente tentadora e tenebrosa, / Tenebrosa serpente de cabelos!..."

Nesse sentido, o poeta recria o imaginário bỉblico do jardim do éden, buscando no signo de Eva a origem e a perpetuação do mal - o mito da mulher serpente, tentadora e tenebrosa. Cabe aqui uma intervenção para retomar o que foi dito anteriormente sobre certa postura de resistência na poética de Cruz e Sousa, a respeito da inaceitação da cultura e da religião europeia e branca. Nos poemas "Afra" e "Dança do Ventre", dois aspectos merecem atenção: o olhar voltado para a mulher africana e a representação da dança árabe, o que confirma essa mirada enviesada para outra cultura, não muito comum na literatura brasileira do século XIX. Exemplifiquemos com trechos desses poemas:

12. SOUSA. Poesias completas de Cruz e Sousa, p. 16.

13. SOUSA. Poesias completas de Cruz e Sousa, p. 29. 


\begin{abstract}
Ressurges dos mistérios da luxúria, Afra, tentada pelos verdes pomos, Entre os silfos magnéticos e os gnomos Maravilhosos da paixão purpúrea. ("Afra")

O ventre, em pinchos, empinava todo Como réptil abjeto sobre o lodo, Espolinhando e retorcido em fúria.

Era a dança macabra e multiforme De um ventre estranho, colossal, enorme, Do demônio sangrento da luxúria! ("Dança do Ventre")
\end{abstract}

Referindo-se a esse embate, o crítico Antonio Carlos Secchin aponta que, "emparedado entre o éter do espírito e o álcool do corpo, o verso de Cruz e Sousa transforma-se no território de batalha entre ambas as forças." ${ }^{15}$ Ludicamente, o crítico toma de empréstimo o substantivo "desterro", estabelecendo um paralelo entre a cidade onde nasceu o poeta e algumas "regiões de desterro" na poesia do catarinense, ressaltando uma região encoberta, onde residiria a problemática do corpo. Nessa mesma perspectiva, Ivone Daré Rabello destaca que a presença do tema sexual em Cruz e Sousa é significativo porque se articula aos temas da dissolução da corporeidade. ${ }^{16}$ Veja-se um fragmento de poema que ilustra essa imagética corporal: "Deslumbramento de luxúria e gozo, / Vem dessa carne o travo aciduloso / De um fruto aberto aos tropicais mormaços". ${ }^{17}$

Essas imagens naturalistas da mulher já foram apontadas por Alfredo Bosi: "Assim, a angústia sexual, manifesta em vários passos, não é apenas resíduo naturalista porque recebe, em geral, tratamento platonizante e abre caminho para um dos processos psicológicos mais comuns no poeta: a sublimação." ${ }^{18}$ É interessante observar que Bosi cita, exatamente, os poemas "Lésbia" e "Braços"

14. SOUSA. Poesias completas de Cruz e Sousa, p. 21 e 24.

15. SECCHIN. Escritos sobre poesia e alguma ficção, p. 40.

16. RABELLO. Um canto à margem. Uma leitura da poética de Cruz e Sousa, p. 193.

17. SOUSA. Poesias completas de Cruz e Sousa, p. 23.

18. BOSI. História concisa da literatura brasileira, p. 272. (Grifo do autor.) 
para comprovar a sua opinião, e acrescenta: "O naturalismo exasperado dos primeiros versos contrai-se no 'espasmo gélido e aflitivo' em que se fundem amor e morte."

Concluindo, aproveitemos o que afirma Antonio Candido, em seu conhecido ensaio "Os primeiros baudelairianos":

Já se tem escrito que o momento culminante da influência de Baudelaire no Brasil foi o Simbolismo, no decênio de 1890 e primeiros anos do seguinte. Momento fin-de-siècle, rosa-cruz e floral, que viu nele sobretudo o mestre da arte-pela-arte, o visionário sensível ao mistério das correspondências e o filósofo, autor de poemas sentenciosos marcados pelo desencanto. (...) e castigo da carne, que se consideravam originárias dele, coadas através de Antero de Quental e Cruz e Sousa. ${ }^{19}$

Os poemas aqui comentados, ainda que de maneira tão breve, revelam esses componentes de amargura, o senso da decomposição e o castigo, segundo as considerações do crítico Antonio Candido. Três estágios que produzem o enfraquecimento e a desintegração material, única maneira de separar o que é essência, espírito, do que é invólucro carnal, algema terrena, pois que do pó fomos tomados, a ele retornaremos!

Feminism, mysticism and liturgy in Cruz e Sousa's poetics

Abstract: Cruz e Sousa's poetry often includes ritualistic, liturgical elements, disclosed through the use of synesthesia and a 'heavenly' vocabulary, which broadens and enhances the symbolism of his texts. In many of his poems, women are described in relation to these religious and mystical elements. However, such constructions should not be taken essentially as manifestations of catholicism. Based on the mystical and naturalistic perspective, the present work intends to discuss the representation of women and the ritualistic and liturgical symbolism in the work of Cruz e Sousa, so as to demonstrate that the presence of

19. CANDIDO. A educação pela noite e outros ensaios, p. 23. (Grifos do autor.) 


\section{religious images and symbols reflects a quest for the transcendental and is not related to any particular religion.}

Keywords: Representations of the feminine, Mysticism, Liturgy.

$$
\text { Referências }
$$

BAUDELAIRE, Charles. As flores do mal. Tradução, introdução e notas de Jamil Almansur Haddad. São Paulo: Editora Abril Cultural, 1984.

BASTIDE, Roger. A poesia afro-brasileira. São Paulo: Martins, 1943.

BOSI, Alfredo. História concisa da literatura brasileira. São Paulo: Cultrix, 1994.

CANDIDO, Antonio. Os primeiros baudelairianos. In: A educação pela noite e outros ensaios. São Paulo: Ática, 1987. p. 23-38.

FERREIRA, Aurélio Buarque de Holanda. Dicionário da língua portuguesa. Rio de Janeiro: Nova Fronteira, 1999.

LÔBO, Danilo. Cruz e Sousa: O assinalado. Revista Travessia, Florianópolis, Universidade Federal de Santa Catarina, n. 26, p. 11-23, 1993.

NUNES, Cassiano. Cruz e Sousa e o mito do poeta como herói moral. Revista Travessia, Florianópolis, Universidade Federal de Santa Catarina, n. 26, p. 25-43, 1993

Ô Catarina! Jornal da Fundação Catarinense de Cultura. Florianópolis - março/abril de 1998 , n. 28.

PEIXOTO, Sérgio Alves. A consciência criadora na poesia brasileira - do Barroco ao Simbolismo. São Paulo: Annablume, 1999.

RABELLO, Ivone Daré. Um canto à margem. Uma leitura da poética de Cruz e Sousa. São Paulo: Edusp, 2006.

SANT'ANNA, Affonso Romano de. O canibalismo amoroso. Rio de Janeiro: Rocco, 1993.

SECCHIN, Antonio Carlos. Escritos sobre poesia e alguma ficção. Rio de Janeiro: EdUERJ, 2003.

SOUSA, Cruz e. Poesias completas de Cruz e Sousa. Edição e introdução de Tasso da Silveira. Rio de Janeiro: Ediouro, 2002. 
